\title{
Studies on the Carburizing Process of AISI 8620 Steel obtained by MIM Technology
}

\author{
Dorin Ioan FELDIOREAN \\ Transilvania University of Brasov, Romania, dfeldiorean@yahoo.com \\ Mircea Horia TIEREAN \\ Transilvania University of Brasov, Romania, mtierean@unitbv.ro
}

\begin{abstract}
These experiments are aimed to highlight the differences that occur in the carburizing process of the metal parts obtained by the MIM technology (Metal Injection Molding), compared to those obtained from round cold drawn bar by CNC and conventional cutting machining (AISI samples). For this purpose, two categories of complex geometry pieces, components of the sewing machine's rotary hook, were used. After tests was observed that depth of the carburized layer is lower for the MIM parts. Using a $5 \mathrm{~kg}$ load, the Vickers hardness measured on the MIM parts surface turned out to be smaller than the AISI samples. Decreasing the load force, the Vickers hardness measured on the MIM sample surface after heat treatment start to increase. In order to obtain the desired hardness after the grinding process, the MIM samples tempering temperature was $130{ }^{\circ} \mathrm{C}$ and for the AISI samples was $170^{\circ} \mathrm{C}$. After the grinding machining, it was also observed that MIM parts had a significant hardness loss compared to the others. These results can be explained due a lower density of the MIM parts $\left(\geq 7.4 \mathrm{~g} / \mathrm{cm}^{2}\right)$ compared to AISI parts $\left(7.81 \mathrm{~g} / \mathrm{cm}^{2}\right)$ and lower content of $\mathrm{Cr}$ and $\mathrm{Mn}$ alloying elements.
\end{abstract}

\section{Keywords}

MIM, heat treatment, hardness, layer, density

\section{Introduction}

Most of the components of the sewing machine have complex a geometry, therefore their execution by machining on lathes and / or milling machines involves high material losses, long machining times, and costs with the machining tools and clamping devices. A viable alternative to conventional cutting machining is the Metal Injection Molding (MIM) technology. This technology removes the barriers of shape complexity, raw material composition, keeping the production costs at a smaller level compared to the conventional processes.

Carburizing is a thermochemical heat treatment procedure involving the diffusion of carbon atoms in the superficial layer of steel parts. The diffusion rate and the depth of carbon penetration in the superficial layer are dependent on a number of factors. Among the most important can be mentioned: the process temperature, the duration of the carburizing process, the carbon and alloying elements content $[1,2]$.

The subject of this study is the bobbin case, one of the main components of the sewing machine's rotary hook; a piece with a complex geometry and high dimensional precision, up to $30 \mu \mathrm{m}$. This part is exposed to a strong wear stress during the sewing process, reason why a carburizing heat treatment is applied in order to increase its surface wear resistance. The goal of this experiment is to observe the differences in carburizing behavior between MIM and classical technology.

\section{Materials and Method}

Two categories of samples were prepared, one category consists of pieces made by the MIM technology of the AISI 8620 steel grade (MIM samples) [3], and the other category consists of pieces made by conventional cutting machining processes from the AISI 5115 steel grade (AISI samples).

The two categories of MIM and AISI samples are made from steel grades with similar chemical composition and are part of the alloyed steels category for carburizing [4]. Both types of samples were subjected to the same heat treatment procedure (carburizing, hardening and tempering), in order to 
obtain $0.5 \mathrm{~mm}$ case hardening depth and 700-750 HV surface hardness. After heat treatment, the samples surface was grinded $0.1 \mathrm{~mm}$ depth.

Performing a comparative analysis of the two manufacturing technologies of the bobbin case in terms of manufacturing costs and execution time, it was emphasized the fact that processing from MIM semifinished products (Figure 1), the manufacturing time is approx. 40\% lower, and production costs dropped by about $25 \%$ compared with AISI parts.
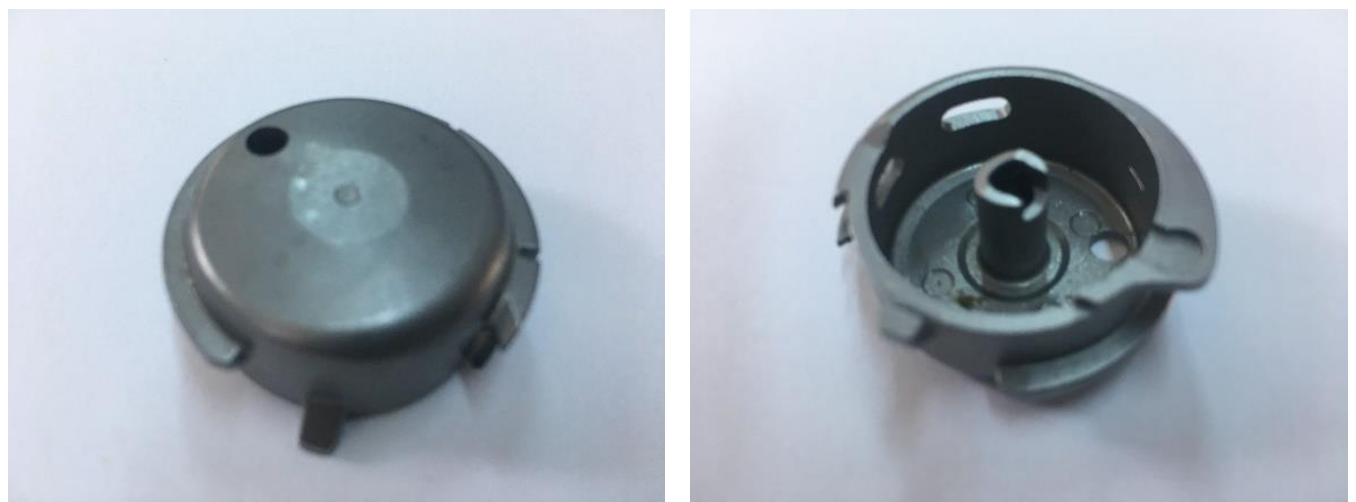

Fig. 1. MIM molded sample

Metal Injection Molding technology involves four main stages: compounding, molding, debinding and sintering $[3,5,6]$. Compounding stage is relevant for the chemical composition of the final part. Molding is usually in molds for plastics injection, at temperatures up to $140^{\circ} \mathrm{C}$. The brown pieces resulting from the debinding process are sintered at about $1300{ }^{\circ} \mathrm{C}$, thus obtaining the finished part.

For the heat treatment of AISI and MIM samples, there were prepared two batches of five samples from each steel grade. Carburizing process (Figure 2) was carried out in a commercial multipurpose atmosphere batch furnace "CBUT 10", electrical heated and with integrated oil quenching system.

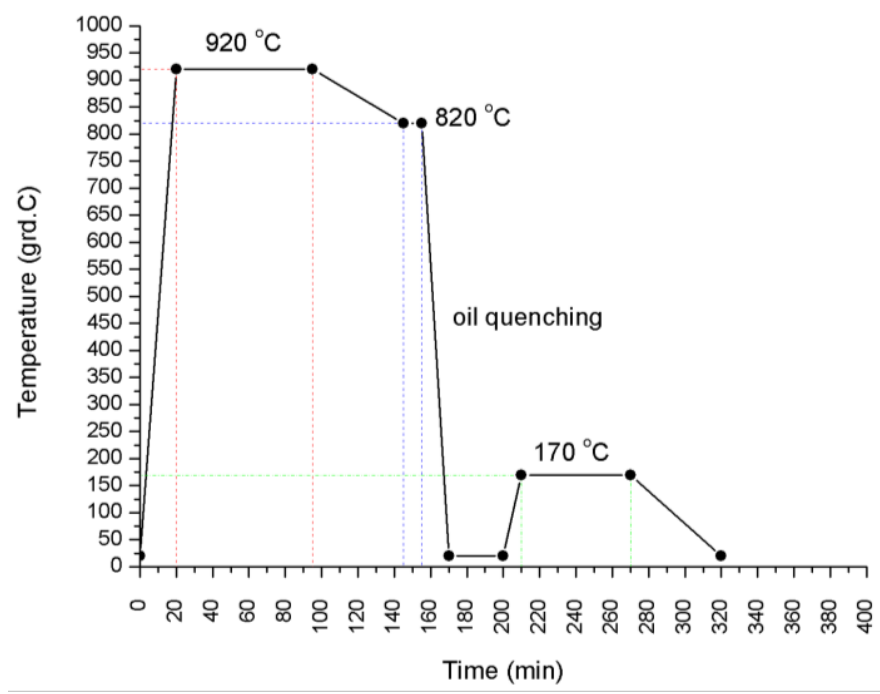

Fig. 2. Carburizing process

Process parameters are as follows: carburizing temperature: $920{ }^{\circ} \mathrm{C}$ using a methane-nitrogenmethanol atmosphere; boost and diffuse cycle: $35 \mathrm{~min}$ boost time $(\mathrm{C}=1.00 \mathrm{wt}$. $\%)$ and $100 \mathrm{~min}$ diffusion time ( $\mathrm{C}=0.8 \mathrm{wt}$. \%); hardening temperature: $820^{\circ} \mathrm{C}$ (in order to avoid distortions); soak time: $10 \mathrm{~min}$; quenching oil temperature: $70^{\circ} \mathrm{C}$. Tempering was performed at two different temperatures: $130{ }^{\circ} \mathrm{C}$ and $170^{\circ} \mathrm{C}$; soak time: $60 \mathrm{~min}$. After the heat treatment, the samples surfaces were grinded $0.1 \mathrm{~mm}$ cut depth.

The chemical composition of the samples was verified after carburizing using an OBLF QS 750 spectrometer. The case hardening depth and surface hardness was measured according to ISO 
2639:2002 [7] (this standard has been revised by ISO 18203:2016 [8]) using a CV-410 DAT Vickers hardness tester. The samples structure was assessed by optical microscopy. The metallographic structure of the two types of samples, AISI and MIM was investigated using the metallographic microscope METTALUX II, the etching reagent used for attack was NITAL in $4 \%$ concentration for about 5 seconds.

\section{Results and Discussion}

The spectral analysis of the chemical composition performed on the two types of samples confirmed that after carburizing prior to grinding, the surface's carbon content is about $0.80 \mathrm{wt} . \%$ and also the fact that the content of the other elements is in accordance with the requirements of the standards, especially in the case of MIM samples (Table1).

Table1. Samples chemical composition according to standards and spectral analysis

\begin{tabular}{|c|c|c|c|c|}
\hline Element & $\begin{array}{c}\text { AISI 8620 Standard } \\
\text { (wt. \%) }\end{array}$ & $\begin{array}{c}\text { MIM samples after } \\
\text { carburizing av. value } \\
\text { (wt. \%) }\end{array}$ & $\begin{array}{c}\text { AISI 5115 } \\
\text { Standard (wt. \%) }\end{array}$ & $\begin{array}{c}\text { AISI samples after } \\
\text { carburizing av. value } \\
\text { (wt. \%) }\end{array}$ \\
\hline $\mathrm{C}$ & $0.17-0.23$ & 0.761 & $0.14-0.19$ & 0.758 \\
\hline $\mathrm{Si}$ & $<0.40$ & 0.361 & $<0.40$ & 0.264 \\
\hline $\mathrm{Mn}$ & $0.65-0.95$ & 0.601 & $1.00-1.30$ & 1.160 \\
\hline $\mathrm{P}$ & $<0.035$ & 0.007 & $<0.035$ & 0.009 \\
\hline $\mathrm{S}$ & $<0.035$ & 0.021 & $<0.035$ & 0.034 \\
\hline $\mathrm{Cr}$ & $0.35-0.70$ & 0.472 & $0.80-1.10$ & 0.995 \\
\hline $\mathrm{Ni}$ & $0.40-0.70$ & 0.659 & $0.40-0.70$ & 0.121 \\
\hline $\mathrm{Mo}$ & $0.15-0.25$ & 0.211 & $0.15-0.25$ & 0.010 \\
\hline
\end{tabular}

The case hardening depth is according to the standard [3], the distance in $\mathrm{mm}$ from the surface to a depth having a hardness inferior limit of 550 HV0.5. After the heat treatment, the micro hardness measurements made with $0.5 \mathrm{~kg}$ load on the samples surfaces shows hardness differences between the AISI and the MIM samples (Figure 3).

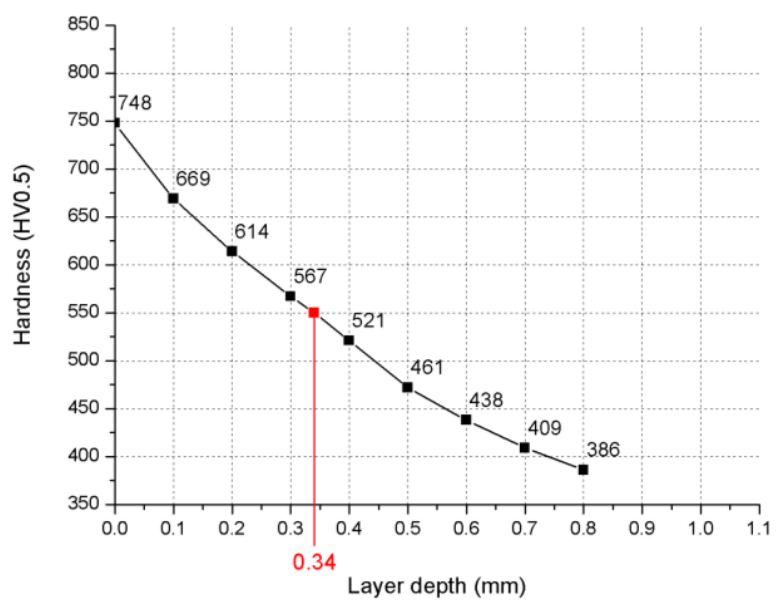

a)

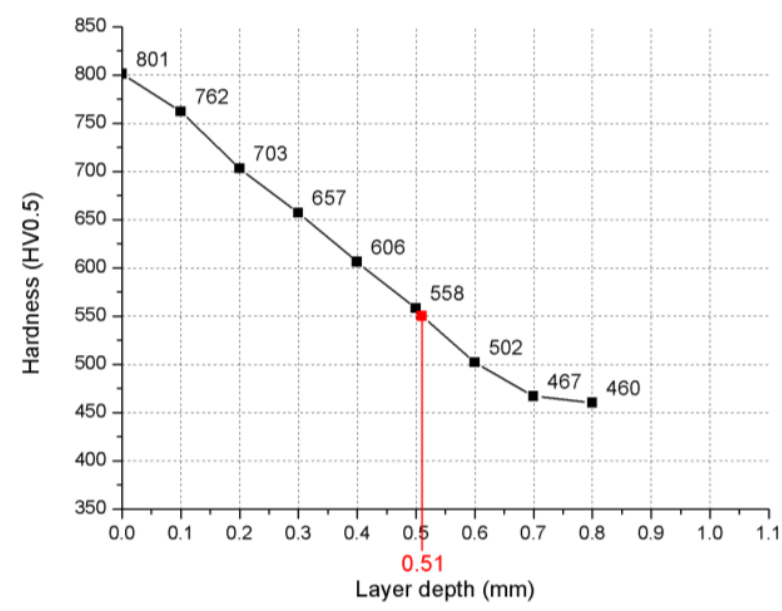

b)

Fig. 3. Case depth after carburizing-quenching and tempering at $170{ }^{\circ} \mathrm{C}$

(a) MIM samples; (b) AISI samples

Although both types of samples were carburized together, in the same batch and with the same process parameters, the micro-hardness profiles revealed that for the MIM samples, the thickness of the carburized layer is with approx. $0.17 \mathrm{~mm}$ lower. It can also be observed that the hardness measured in the AISI samples core is higher than that of the MIM samples, due to the higher content of the $\mathrm{Mn}$ and $\mathrm{Cr}$ alloying elements. 
According the standard [9], usually for this case hardening depth the Vickers hardness measurements can be made with $5 \mathrm{~kg}$ load. Nevertheless in the case of MIM samples the measurements made, point out that there are differences between the Vickers hardness values measured with $5 \mathrm{~kg}$ load, $1 \mathrm{~kg}$ load and those with $0.5 \mathrm{~kg}$ load. The hardness values decrease as the load force increases (Figure 4).

The results of the measurements show that the MIM samples have a very similar behaviour to the sintered parts, they show a macro hardness (apparent hardness) and a micro hardness (metallic phase hardness)[10].

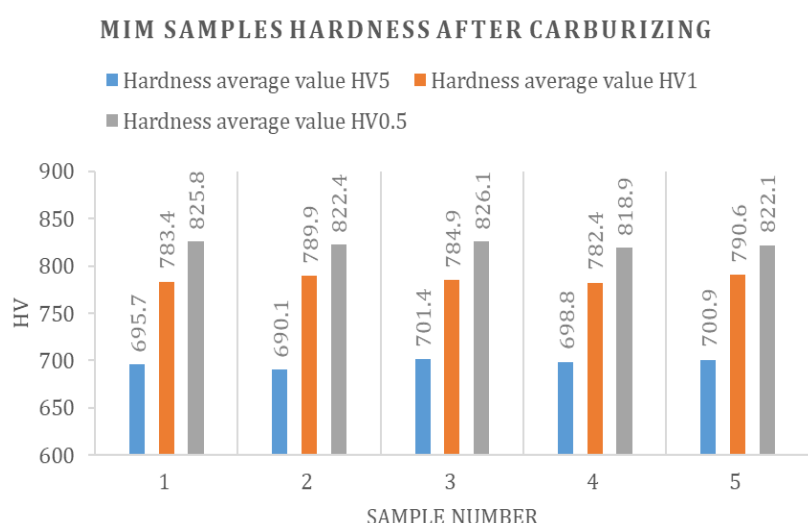

a)

MIM SAMPLES HARDNESS AFTER CARBURIZING AND TEMPERING AT $170^{\circ} \mathrm{C}$

- Hardness average value HV5 Hardness average value HV1

- Hardness average value HV0.5

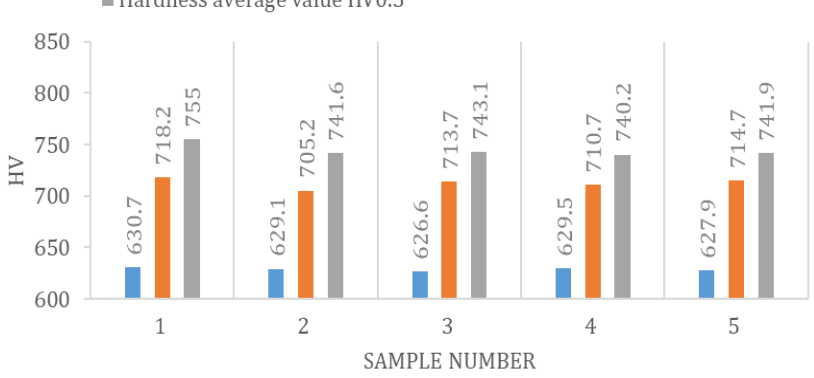

c)

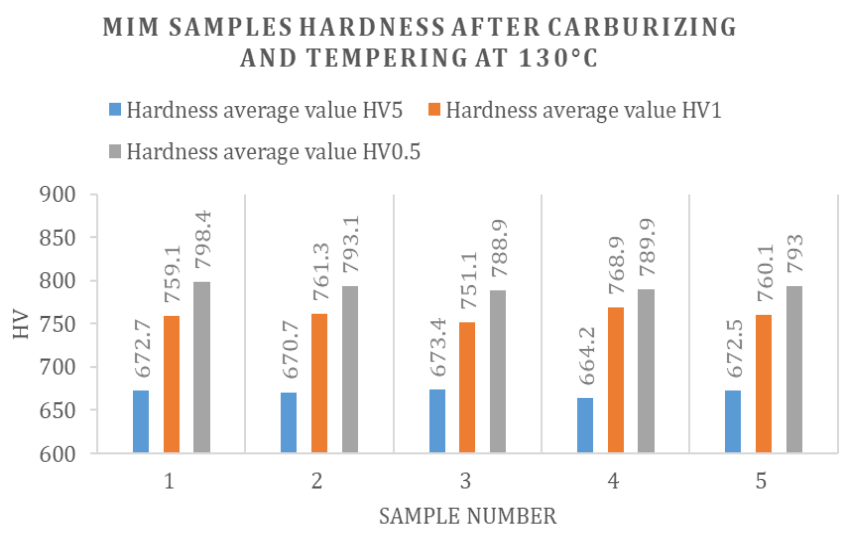

b)

MIM SAMPLES HARDNESS AFTER CARBURIZING TEMPERINGAT $170^{\circ} \mathrm{CAND}$ GRINDING

- Hardness average value HV5 Hardness average value HV1

n Hardness average value HV0.5



d)

Fig. 4. The hardness of MIM samples in different stages of processing (a) carburized; (b) carburized and tempered at $130^{\circ} \mathrm{C}$; (c) carburized and tempered at $170{ }^{\circ} \mathrm{C}$; (d) carburized, tempered at $170^{\circ} \mathrm{C}$ and grinded

Each average hardness value was calculated based on a minimum of six measurements. In order to increase the precision of Vickers hardness measurements made with the small load $(0.5 \mathrm{~kg})$, case in which for the human eye it is harder to estimate the indent tips dimensions [11], more than 10 measurements were made on each sample. Over 600 measurements were performed in total on the MIM and AISI samples.

Unlike the MIM samples, for the AISI samples, the hardness values measured with $1 \mathrm{~kg}$ and $0.5 \mathrm{~kg}$ are almost identical. Hardness differences due to the load force were only observed at $5 \mathrm{~kg}$ load (Figure 5). The higher penetration depth of the diamond indenter causes for this situation slightly lower hardness.

Hardness measurements made on AISI samples show smaller hardness losses due to tempering and grinding process compared to MIM samples. In order to maintain the same hardness values between the two types of samples, the tempering temperature for MIM samples should be lower, respectively $130{ }^{\circ} \mathrm{C}$, compared to $170^{\circ} \mathrm{C}$ for AISI samples.

Before and after the heat treatment the microstructure was assessed by optical microscopy. Figure 6 show the MIM samples microstructure prior to the carburation process. Etching with $4 \%$ Nital reagent, a typical ferrite-pearlite microstructure can be observed (Figure 6). 
RECENT, Vol. 19, no. 2(55), November, 2018

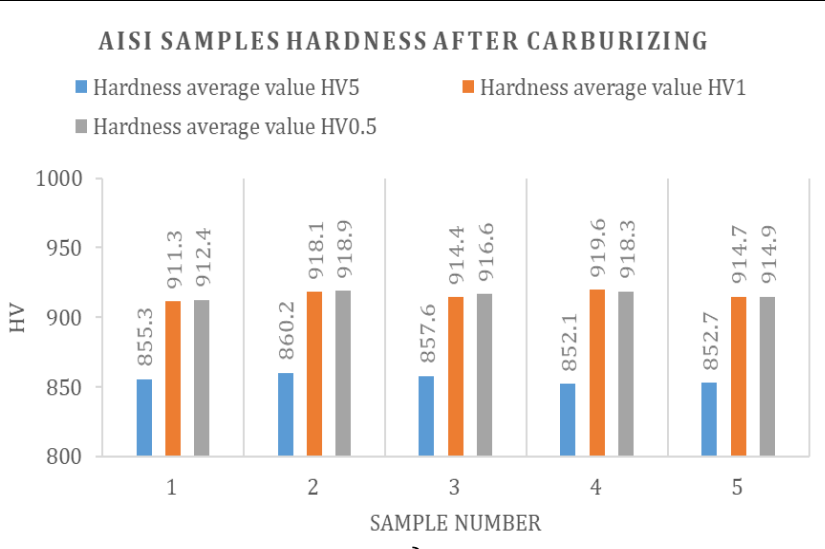

a)

AISI SAMPLES HARDNESS AFTER CARBURIZING AND TEMPERING AT $170^{\circ} \mathrm{C}$

- Hardness average value HV5

- Hardness average value HV0.5

- Hardness average value HV1



c)
AISI SAMPLES HARDNESS AFTER CARBURIZING AND TEMPERING AT $130^{\circ} \mathrm{C}$

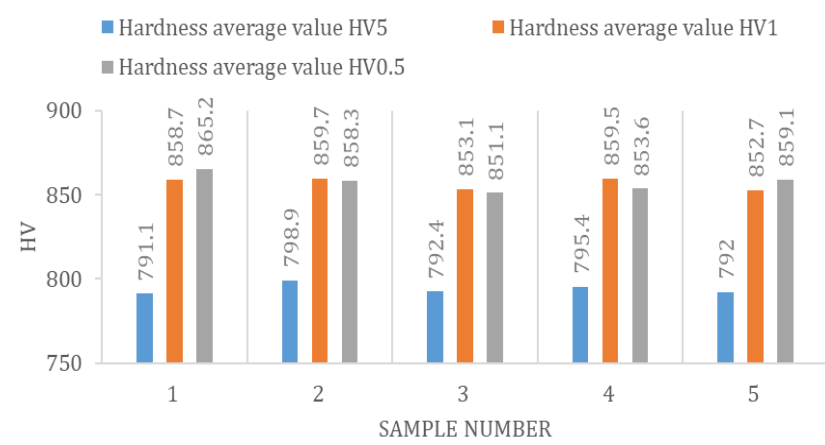

b)

AISI SAMPLES HARDNESS AFTER CARBURIZING TEMPERINGAT $170^{\circ} \mathrm{C}$ AND GRINDING

- Hardness average value HV5 Hardness average value HV1 ๑ Hardness average value HV0.5

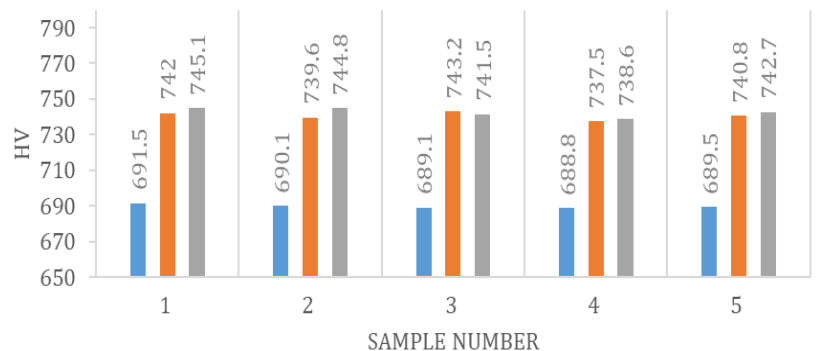

d)

Fig. 5. The hardness of AISI samples in different stages of processing (a) carburized; (b) carburized and tempered at $130{ }^{\circ} \mathrm{C}$; (c) carburized and tempered at $170{ }^{\circ} \mathrm{C}$; (d) carburized, tempered at $170^{\circ} \mathrm{C}$ and grinded

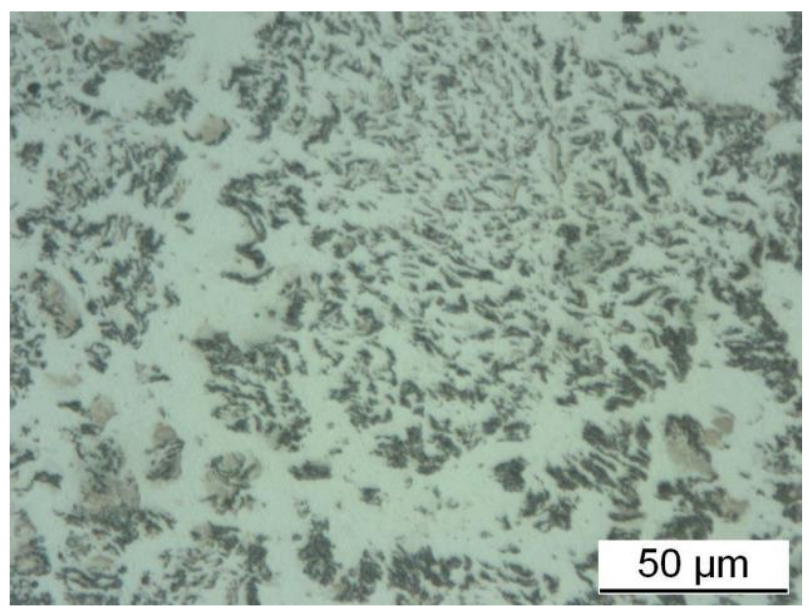

Fig. 6. MIM sample prior to heat treatment: ferrite-pearlite microstructure

Both carburized, quenched and tempered samples MIM and AISI show a hard and brittle martensitic microstructure in the near-surface carburized layer. Figure 7a corresponding to MIM samples shows a martensitic primary structure with undissolved carbides and a small amount of retained austenite (untransformed austenite) light colored, present among the tempered martensite laths. On the other hand the AISI sample micrograph (Figure 7b) shows a finer-grained tetragonal martensitic microstructure compared to the MIM samples with undissolved small white carbides particles, uniformly distributed; no retained austenite was observed. 




a)

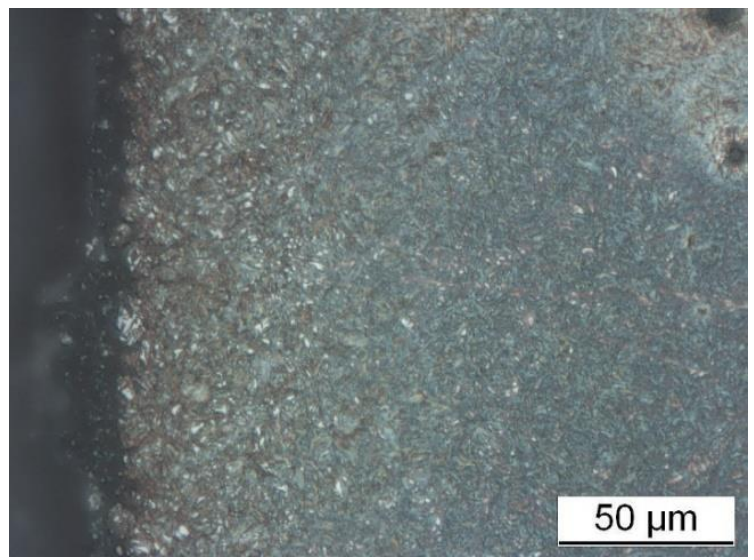

b)

Fig. 7. Microstructure after carburizing-quenching and tempering

(a) MIM samples; (b) AISI samples

\section{Conclusions}

After carburizing and tempering process it has been noticed that the in contrast with the AISI samples, the MIM samples shows a notable smaller depth of the carburized layer, though both types of samples were carburized together with the same process parameters. Using a $5 \mathrm{~kg}$ load, the Vickers hardness measured on the MIM samples surfaces drops with more than 100 units compared to the AISI samples. Decreasing the load force, the Vickers hardness measured on the MIM sample surface after the heat treatment start to increase. Experiments made have shown that the MIM samples surface hardness should be measured with a max. $0.5 \mathrm{~kg}$ load. After the grinding machining it was also observed that the MIM parts had a significant hardness decrease compared to the AISI samples (Figure 8).

\section{HARDNESS EVOLUTION AISI VS. MIM}

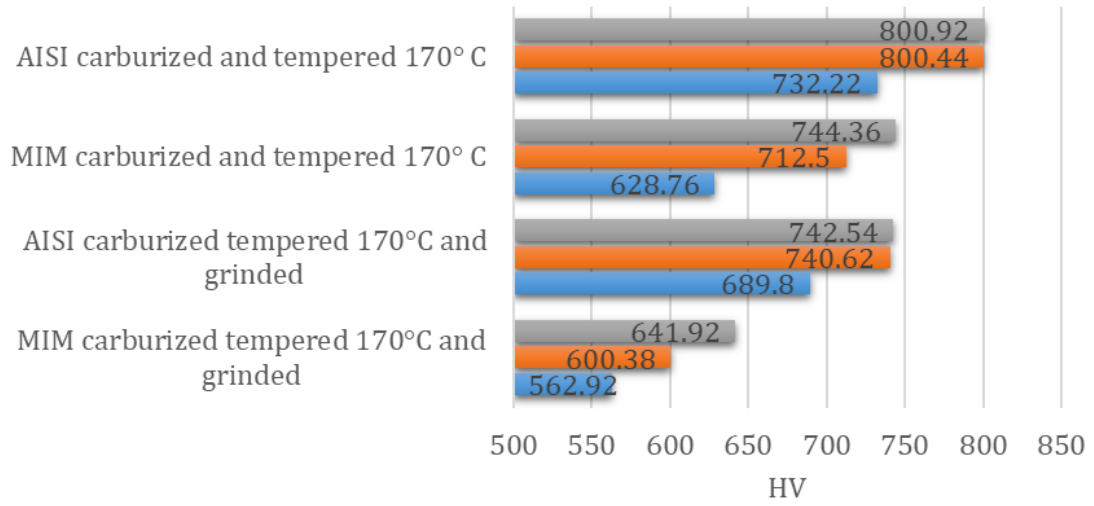

mardness av. value HV0.5 mardness av. value HV1 a Hardness av. value HV5

Fig. 8. Hardness comparison AISI vs MIM

In order to obtain the desired hardness after the heat treatment and grinding, MIM samples tempering temperature was $130{ }^{\circ} \mathrm{C}$ in contrast to $170{ }^{\circ} \mathrm{C}$ for the AISI samples. If the dimensional precision conditions and/or the surface quality of the MIM parts must be higher (Ra $<0.8 \mu \mathrm{m})$ and therefore subsequent operations of grinding and finishing are needed, this phenomenon should be considered.

Even though the standards show that the parts obtained by MIM technology have generally the same density as those obtained from round cold drawn bar (full-density material) by CNC and conventional cutting machining, experiments showed that approach of the carburizing process and that of the hardness measuring must be different. Their behaviour is very close to that of sintered materials, showing a macro hardness (apparent hardness) and a micro hardness (metallic phase hardness). 
This results can be explained due a lower density of the MIM parts $\left(\geq 7.4 \mathrm{~g} / \mathrm{cm}^{2}\right)$ [3] compared to AISI parts $\left(7.81 \mathrm{~g} / \mathrm{cm}^{2}\right)[12,13]$ and lower content of $\mathrm{Cr}$ and Mn alloying elements.

\section{References}

1. Karabelchtchikova 0. (2007): Fundamentals of Mass Transfer in Gas Carburizing. Dissertation, Worcester Polytechnic Institute, MA, USA, https://web.wpi.edu/Pubs/ETD/Available/etd-121807-234414/unrestricted/ Karabelchtchikova.pdf

2. Wells C., Mehl R.F. (1940): Rate of Diffusion of Carbon in Austenite in Plain Carbon, in Nickel and in Manganese Steels. American Institute of Mining Metallurgical Engineers, Technical Publication No. 1180, http://www.aimehq.org/doclibrary-assets/books/Metals\%20Technology,\%201940,\%20Vol.\%20VII/ T.P.\%201180.pdf

3. ${ }^{* * *}$ (2008): Catamold 8620

4. ${ }^{* * *}$ (2008): EN ISO 10084: Case hardening steels-Technical delivery conditions

5. Bloemacher M., Weinand D. (1997): Catamold TM - A new direction for powder injection molding. Journal of Materials Processing Technology, ISSN 0924-0136, 63(1), p. 918-922, DOI: 10.1016/S0924-0136(96)00014-3

6. ${ }^{* * *}$ (2003): Catamold $\AA$ Feedstock for Metal Injection Molding: Processing - Properties - Applications. Technical Information, BASF AG

7. *** (2002: EN ISO 2639: Steels - Determination and verification of the depth of carburized and hardened cases

8. *** (2016): EN ISO 18203: Steel - Determination of the thickness of surface-hardened layers

9. *** (2018): EN ISO 6507-1: Metallic materials - Vickers hardness test. Part 1: Test method

10. ${ }^{* * *}$ (2005): EN ISO 4498: Sintered metal materials, excluding hardmetals-Determination of apparent hardness and microhardness

11. Strnad G., Jakab-Farkas L. (2014): Improving the Accuracy of Low-load Vickers Microhardness Testing of Hard Thin Films. Procedia Technology, ISSN 2212-0173, Vol. 12, p. 289-294, doi: 10.1016/j.protcy.2013.12.488

12. ${ }^{* * *}$ (2018): 16MnCr5 Material data sheet. https://steelnavigator.ovako.com/steel-grades/16mncr5/

13. ${ }^{* * *}$ (2016): SIQUAL 7131 Steel. https://steelselector.sij.si/steels/EC80.html

Received: 29 August 2018; Accepted: 25 September 2018 